\title{
Morphological features of the venous bed of the heart of the Baikal seal
}

\author{
Vyacheslav Tarasevich* \\ Irkutsk State Agrarian University Named after A.A. Ezhevsky, Irkutsk, Russian Federation
}

\begin{abstract}
The article describes the features of venous blood outflow from the heart in the Baikal seal. The objects for the study were corrosion preparations of 11 hearts of the Baikal seal aged from 1 month to 10 years. In our research we used the methods of preparation, filling of vessels with the use of "Kudo" mounting foam, photographing and sketching the branching of vessels. It was established that in the Baikal seal, the outflow of venous blood occurs through the prominent coronary sinus and the large, intermediate, oblique vein of the left atrium, the middle and right heart veins that flow into it. In $18.2 \%$ of hearts, a coronary valve was found at the border of the great heart vein and the coronary sinus. The great heart vein begins above the apices of the heart and is formed from the fusing of the 6-11 collateral veins of the wall of the right ventricle, the venous pericardial plexus, and 9-16 branches on the side of the left ventricle. The most variable is the intermediate (marginal) branch, which in most cases has only one branch, however, in $18.2 \%$ of cases there are two ones or in $9.1 \%$ of cases, there are intermediate branches with a common trunk. The middle vein of the heart is located in the sub-sinus sulcus and anastomoses with the branch of the great vein of the heart, in $9.1 \%$ of cases, the valve of the coronary sinus was found at the border with the coronary sinus. The right veins of the heart have 5-6 branches, among which the marginal ones are the most prominent. $27.3 \%$ of Baikal seals have a venous sinus formed from the fusion of the middle and right coronary veins, as well as a duct connecting the large cardiac vein with this sinus.
\end{abstract}

\section{Introduction}

The heart (cor, cardia) is a hollow muscular organ that promotes its movement through the circulatory circles by creating a change in the level of blood pressure. At the same time, the movement of blood in the heart is carried out from the atria to the ventricles, where it is further pushed into the aorta and pulmonary arteries, the large and small circles of blood circulation. The blood supply to the organ itself occurs during the diastole and the outflow of venous blood during the systole of the heart. The main sources of arterial blood supply to the heart of animals are the left and right coronary arteries, and the venous bed is represented by the large, intermediate, middle and right veins [3, 4].

The available literature presents the features of the branching of the heart veins in the European bison [8], porcupine [7], Anglo-Nubian goats [11, 12], New Zealand white rabbit [16], domestic dog and fur-bearing animals [3], as well as some aquatic mammals [13, 14]. There are published works of Tarasevich V.N. on the morphology of the heart of the Baikal seal and the peculiarities of its blood supply $(2020,2021)[4,5,15]$.

However, in the available literature, we did not find data on the topography and features of the branching of the coronary veins of the Baikal seal, which was the purpose of our study.
The study was aimed was to analyse the venous outflow of blood from the heart in the Baikal seal.

\section{Materials and methods}

For the study, we used hearts taken from the Baikal seal bodies of different age groups (1 month $(n=2) ; 5-6$ months $(n=4) ; 1$ year $(n=2) ; 6$ years $(n=1)$ and 10 years $(n=2))$. For good visualization and further study of the branching, the filling of the venous vessels of the heart was performed using mounting foam (Kudo). The corresponding vessels of the heart were filled individually, using an adapter and a needle of the appropriate diameter, as well as through the coronary sinus of the heart. After the foam solidified, the wet preparations were placed in a $10 \%$ formalin solution, for longer storage. Methods of studying the corrosion preparations of the heart vessels included conventional dissection, photographing and sketching the branching of the vessels.

\section{Results and Discussion}

The main collectors through which the outflow of venous blood from the structures of the heart is carried out are the large, intermediate, middle and right heart veins. At the same time, the main flow of venous blood

*orresponding author: tarasevich7239@mail.ru 
passes through the coronary sinus, which in the form of a slit-like space is adjacent to the right atrium.

The coronal sinus (sinus coronarius) of the Baikal seal has a cone-shaped form, located in the coronal furrow, where it is slightly shifted to the left relative to the subsinuous furrow. It passes ventrally from the opening of the caudal vena cava, where it flows into the right atrium. The presence of a coronal sinus was noted in the New Zealand rabbit [16] and other animals, except for such representatives as the North American beaver [9] and the Eurasian lynx [2].

Two (18.2\%) individuals of the Baikal seal were found to have a venous valve at the junction of the great cardiac vein to the coronary sinus. The valve has two flaps, relatively delicate and thin membranes, which are arranged in such a way that one of them is located below and responds to the reverse flow of blood, and the other is on top (Figure 1). According to V.N. Zhedenov (1954), the presence of one or two semilunar vein valves is sometimes observed in animals [1].

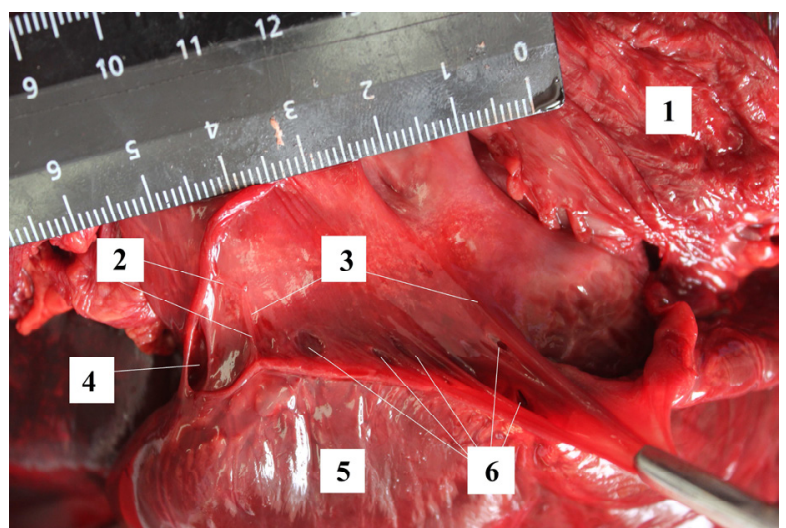

Figure 1. The coronary sinus, Baikal seal 10 years old, ㅇ:

1 - the right atrium;

2 - the semilunar valves of the great heart vein;

3 - the coronary sinus;

4 - the mouth of the great heart vein;

5 - the wall of the left ventricle;

6 - the openings on the side of the trunk of the middle and right heart veins.

The large heart vein ( $\mathrm{v}$. cordis magna) is located in the paraconal and left coronal sulcus, corresponding to the branching of the left coronary artery (Figure 2).

It begins with two branches above the apices of the heart, passes in the paraconal interventricular sulcus and from the pulmonary trunk, rounding the coronal sulcus of the heart, flows into the coronal sinus. On its way, it provides an outflow of venous blood from the wall of the right ventricle (6-11 collateral branches), the left atrium, the pericardium and the wall of the left ventricle. From the left ventricle, it receives voluminous collateral veins accompanying the diagonal branches of the left coronary artery (5-12 branches). In the area of the left coronal sulcus, the large heart vein receives inflows from the branches of the venous plexus, which provides blood outflow from the pericardial region. It should be noted that the presence of one trunk of the collector vessel was noted in the majority of individuals of the Baikal seal, and the presence of two main vessels, which go in most of the paraconal interventricular sulcus with the same artery was noted in one individual (9.1\%) (Figure 3).

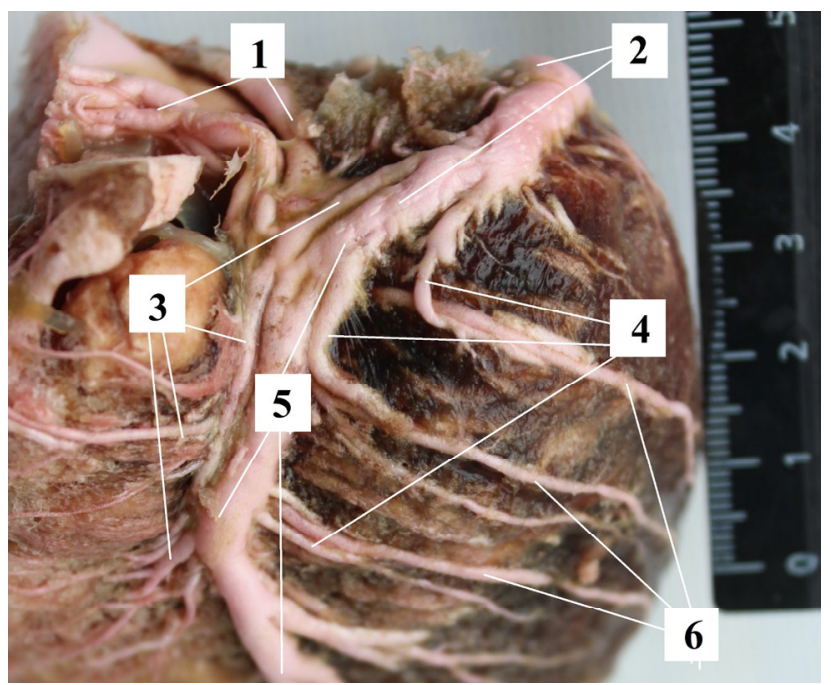

Figure 2. The corrosion preparation of heart vessels, Baikal seal 6 months, $\sigma^{\top}$ :

1 - the venous plexus of vessels;

2 - the envelope of the great heart vein;

3 - the collateral veins of the right ventricle;

4 - the collateral branches of the left ventricle;

5 - the paraconal interventricular branch of the great heart vein;

6 - the diagonal arteries of the left ventricle.

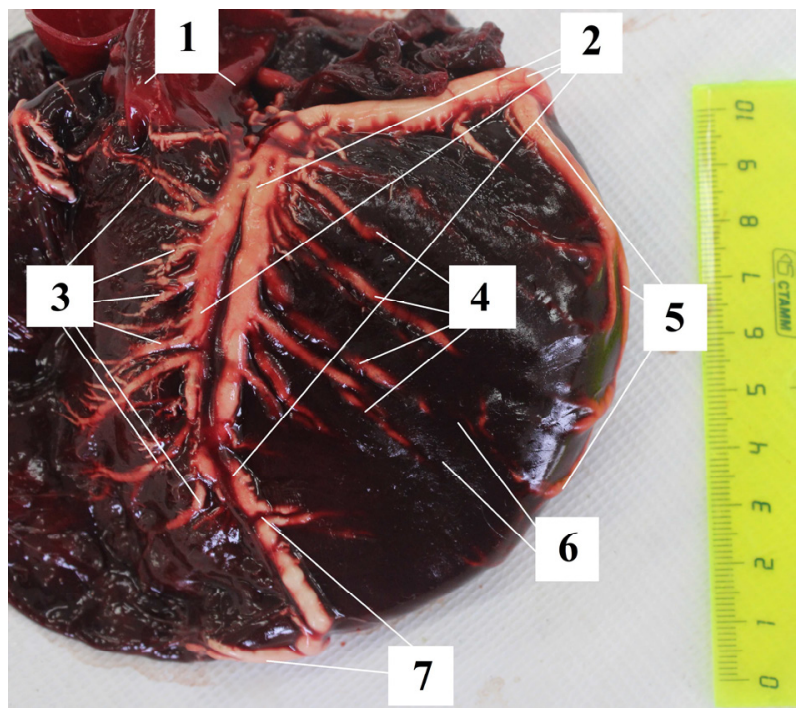

Figure 3. The cranio-ventricular surface of the heart, Baikal seal 10 years old, $\widehat{\jmath}$ :

1 - the pulmonary trunk;

2 - the large heart vein;

3 - the collateral branches of the right ventricle;

4 - the collateral branches of the left ventricle;

5 - the intermediate (marginal) vein;

6 - the anastomoses between the collateral branches of the large heart and intermediate vein; 7 - the branches of the middle heart vein. 
In H. Smodlaka et al. (2009), data on the presence of a pericardial venous plexus in ringed seals are presented [13]. One of the most voluminous tributaries of the great heart vein is the intermediate (marginal) branch (ramus intermedius). It provides an outflow of venous blood from the lateral part of the ventricle and in most cases, it begins above the tip of the lateral part of the ventricle. It can have either a marginal position, or it can be shifted to the edge of the caudo-dorsal surface of the ventricle. In the studied representative, we found three variants of the falling of the intermediate branch in the envelope of the great heart vein: 1) where it has one prominent branch that collects venous blood from the entire lateral part of the left ventricle in $72.7 \%$; 2) the presence of two independent branches in $18.2 \%$ of cases (Figure 4); and 3 ) the confluence is in the form of a common short trunk united from two intermediate branches of the veins (Figure 5).

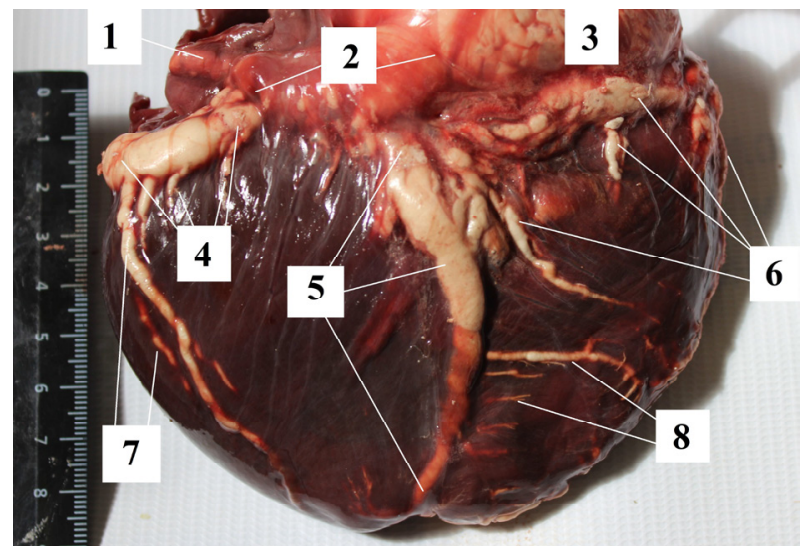

Figure 4. The caudo-dorsal surface of the heart, Baikal seal 6 years old, $q$ :

1 - the oblique vein of the right atrium;

2 - the coronal sinus;

3 - the right atrium;

4 - the large heart vein;

5 - the middle heart vein;

6 - the right heart veins;

7 - the intermediate branch of the large heart vein;

8 - the collateral branches of the wall of the right ventricle.

It should be noted that several collateral vessels adjacent to the main ones not immediately but only after a while, accompanying them at some distance. It makes it possible to shift them to the zone of least resistance of the blood (Figure 4).

The Baikal seal has anastomoses between the branches of the large and middle veins of the heart, as well as the intermediate one. The presence of anastomoses was noted by several authors, in the European bison and goats of the Anglo-Nubian breed [8, 11], however, in such a representative as the Van cat, they were completely absent [6].

The middle vein of the heart ( $\mathrm{v}$. cordis media) collects blood from the apex of the heart, the dorsocaudal surface of the interventricular septum and the walls of the right and left ventricles. It begins at the apex of the heart, the cranio-ventricular surface of the heart, in the form of two branches, one of which anastomoses with the large cardiac vein, and passing between the apices of the heart in the subsinuous furrow, it goes up to the base of the ventricles (Figure 6).

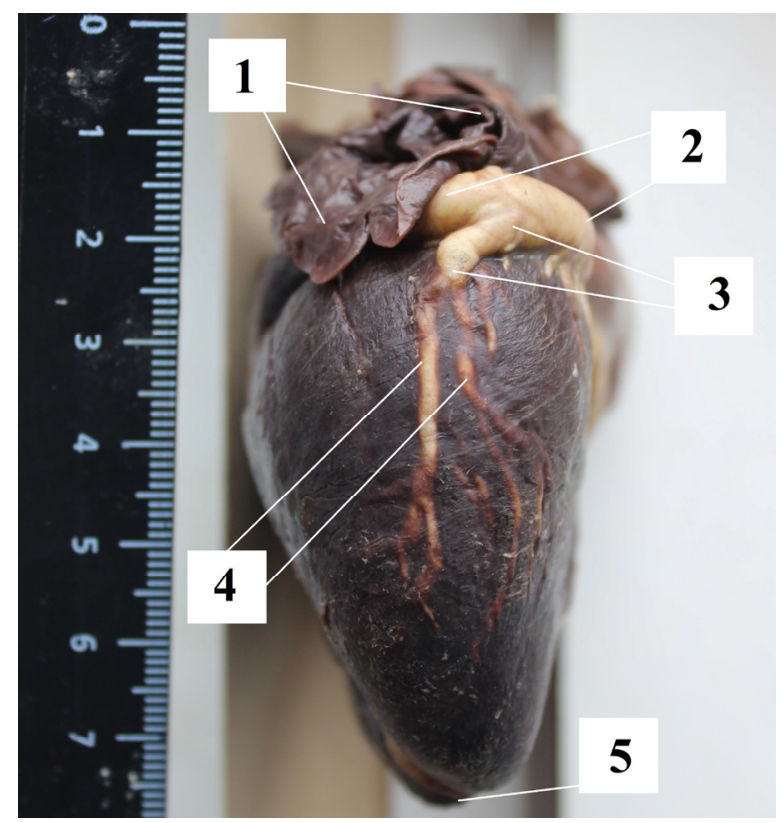

Figure 5. Lateral surface of the left ventricle of the heart, Baikal seal 1 month, ${ }^{\lambda}$ :

1 - the left atrium;

2 - the great heart vein;

3-the common trunk of the intermediate branches of the great heart vein;

4 - the intermediate branches of the great heart vein;

5 - the tip of the left ventricle.

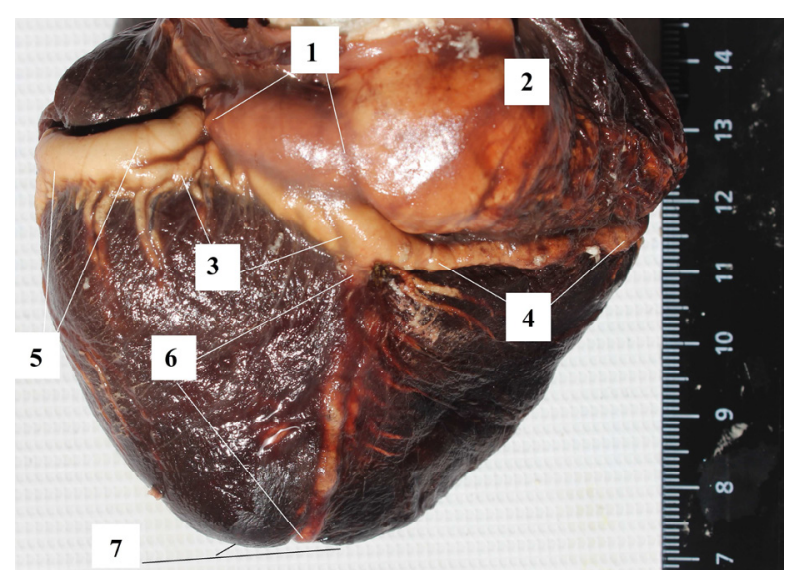

Figure 6. The dorso-caudal surface of the heart, Baikal seal 1 month, $\sigma^{\top}$ :

1 - the coronary sinus of the heart;

2 - the right atrium;

3 - the duct connecting the large and middle heart veins;

4 - the right vein;

5 - the large heart vein;

6 - the middle heart vein;

$7-$ the apices of the heart. 
On its way, it collects venous blood from the walls of the right and left ventricles. In the area of the coronal sulcus, together with the right heart vein, it enters the coronary sinus. In $9.1 \%$ of cases, a semilunar bicuspid valve was found at the fusion of the middle heart vein, creating an obstacle to the reverse flow of blood. The information about the presence of a valve in the mouth of the middle vein is noted in the work of Zhedenov V.N. (1954) [1].

According to Khvatov V., Shchipakin M. (2020), in goats of the Anglo-Nubian breed, the middle heart vein independently flows into the coronary sinus, and is formed by two branches, from the wall of the left ventricle and in the form of an anastomosis from the branches of the large heart vein [12].

It should be noted that the right heart veins (vv. cordis dexter) provide the outflow of venous blood from the base of the pulmonary trunk, the aorta, the right atrium and the ventricle (Figure 7).

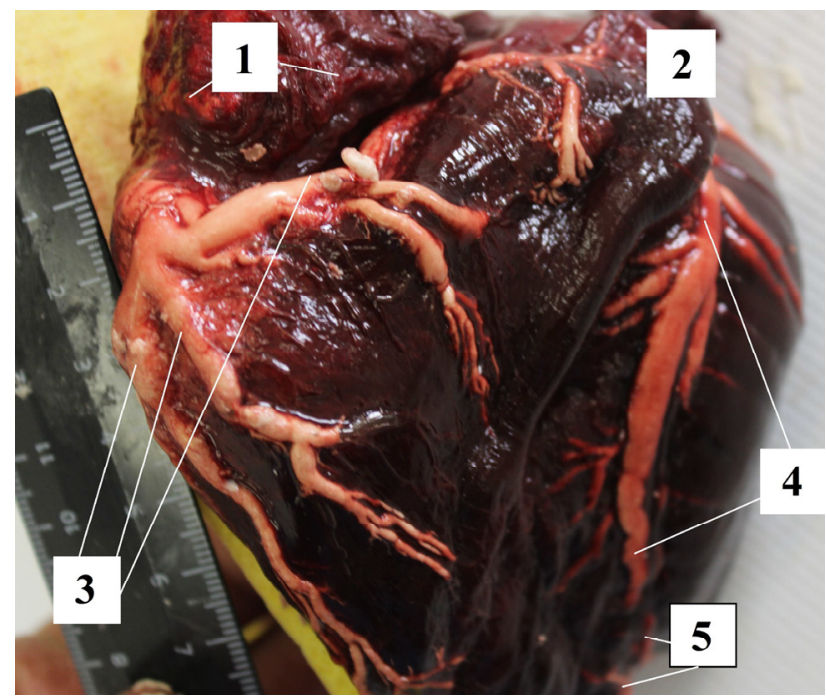

Figure 7. Caudo-dorsal surface of the heart, Baikal seal 6 years old, + :

1 - the right atrium;

2 - the pulmonary trunk;

3 - the right heart veins;

4 - the large heart vein;

5 - the middle heart vein.

There are from 5 to 6 branches, three of which collect venous blood from the side of the heart and anastomose with the apical branch of the middle heart vein. The right heart veins communicate not only with the cavity of the right atrium, but also pass into the mouth of the middle coronal vein or the coronal sinus. In $27.3 \%$ of the hearts, we found the presence of a venous sinus formed as a result of the fusion of the middle and right coronary veins, as well as the duct connecting the large cardiac vein to this sinus. In the New Zealand white rabbit, the middle heart vein and the right circumferential vein shared a common trunk (32\% of cases) [16].

\section{Conclusion}

Thus, in the Baikal seal, the outflow of venous blood occurs through the prominent coronal sinus and the large, intermediate, oblique vein of the left atrium, the middle and right heart veins that flow into it. The presence of a coronal sinus valve was observed in $18.2 \%$ of hearts. The great heart vein begins above the apices of the heart and is formed from the fusing of the 6-11 collateral veins of the wall of the right ventricle, the venous pericardial plexus, and 9-16 branches on the side of the left ventricle. The most variable is the intermediate (marginal) branch, which in most cases has only one branch, however, in $18.2 \%$ of cases there are two ones or in $9.1 \%$ of cases, there are intermediate branches with a common trunk. The middle vein of the heart is located in the sub-sinus sulcus and anastomoses with the branch of the great vein of the heart, in $9.1 \%$ of cases, the valve of the coronary sinus was found at the border with the coronary sinus. The right veins of the heart have 5-6 branches, among which the marginal ones are the most prominent. In $27.3 \%$ of Baikal seals, a venous sinus was found, formed from the fusion of the middle and right coronary veins, as well as the duct connecting the large cardiac vein with this sinus.

\section{References}

1. V.N. Zhedenov Lungs and heart of animals and humans (Moscow.: Sovetskaya nauka, 1954)

2. N.V. Zelenevsky, K.N. Zelenevsky, D.V. Vasiliev Materials of the international research conference dedicated to the 80th anniversary of the Irkutsk State Agricultural Academy and the 10th anniversary of the first graduation of veterinarians pp. 62-71, (Irkutsk, November 1011, 2014).

3. M.V. Ozhogina Omsk Scientific Bulletin. 5 (39), 142-145, (2006).

4. V.N. Tarasevich, N.I. Ryadinskaya Bulletin of the IRGSHA. 97, 145-154, (2020)

5. V.N. Tarasevich, N.I. Ryadinskaya Morphology. 157 (2-3), 208-208, (2020)

6. G. Aksoy, H. Karadag, Z. Ozudogru Anatomia, histologia, embryologia. 32 (3), 129-133, (2003) DOI 10.1046/j.1439-0264.2003.00444.x

7. Ö. Atalar et al. Anatomia, histologia, embryologia. 33 (4), 233-235, (2004) DOI 10.1111/j.1439-0264.2004.00542.x

8. K. Barszcz et al. BMC veterinary research. 16 (1), 1-8, (2020).

9. A. Bisaillon Anat. Anz., 150, 248-258, (1981)

10. R. J. Harrison, J. D. W. Tomlinson Journal of Zoology 126(2), 205-234, (1956) DOI:10.1111/j.1096-3642.1956.tb00433.x

11. V. Khvatov, M. Shchipakin Advances in Animal and Veterinary Sciences. 8(10), 1057-1059, 
(2020)

DOI:

10.17582/journal.aavs/2020/8.10.1057.1062

12. V. Khvatov, M. Shchipakin International Transaction Journal of Engineering, Management and Applied Sciences and Technologies. 11(16), 11A16T, (2020) DOI: 10.14456/ITJEMAST.2020.32

13. H. Smodlaka, R.W. Henry, R.B. Reed Anatomia, Histologia Embryologia. 38 (3), 161-168, (2009). DOI 10.1111/j.1439-0264.2008.00896.x.

14. H. Smodlaka et al. Anatomia, histologia, embryologia, 39(3), 178-185, (2010). DOI 10.1111/j.1439-0264.2010.00994.x

15. V.N. Tarasevich E3S Web of Conferences. 254, 08009, (2021).

DOI: 10.1051/e3sconf/202125408009

16. A. Yoldaş, İ. H. Nur Iranian Journal of Veterinary Research. 13(3), 227-233, (2012) 